\title{
DERROTABILIDAD DE LA CARGA DE LA PRUEBA EN LA RESPONSABILIDAD CONTRACTUAL: HACIA LA FACILIDAD PROBATORIA EN CHILE
}

\author{
BURDEN OF PROOF DEFEASIBILITY \\ IN CONTRACTS LIABILITY: TOWARDS \\ EVIDENCE EASINESS IN CHILE
}

\section{POSSIBILITÉ DE RENVERSER LA CHARGE DE LA PREUVE DANS LA RESPONSABILITÉ CONTRACTUELLE: VERS LA FACILITÉ PROBANTE AU CHILI}

\section{Pablo Bravo-Hurtado*}

Este trabajo analiza, desde la perspectiva de la teoría del razonamiento jurídico, el art. 1698 del $C C$ chileno, que contiene la regla general sobre distribución de la carga de la prueba. A partir del marco conceptual de Frederick Schauer -que entiende las reglas prescriptivas como generalizaciones con justificaciones subyacentes- se propone demostrar que la distribución de cargas que hace el 1698 es derrotable. Aquí se exhibirán casos reconocidos por la jurisprudencia en que la generalización del 1698 no sirve a su justificación subyacente y, en consecuencia, los jueces derrotan su aplicación. Los hechos impeditivos y modificativos, por una parte, y la facilidad probatoria, por la otra, son las principales hipótesis de derrotabilidad sobre la distribución de la carga que hace el articulo 1698 del $C C$.

Palabras clave: carga de la prueba, derrotabilidad, facilidad probatoria, reforma procesal civil.

* Profesor de Derecho Procesal, Universidad Católica de Temuco. Dirección postal: Manuel Montt No 56, Temuco. Artículo recibido el 19 de marzo de 2013 y aceptado para su publicación el 20 de mayo de 2013. Correo electrónico: pbravohurtado@uct.cl. 


\begin{abstract}
This paper analyzes from the perspective of the legal reasoning theory the article 1698 of the Chilean Civil Code that contains the general rule on the distribution of the burden of proof. From Frederick Schauer's conceptual framework -that understands the prescriptive rules as generalization with background justifications- I propose to demonstrate that the 1698' distribution of burdens can be defeated. Here will be shown that there is case-law in which the 1698' generalizations have no use for its background justification and, accordingly, the judges defeat its application. The impeditive and modification facts, in one hand, and the evidence easiness, in the other, are the main hypothesis of defeasibility on the burden distribution made by the article 1698 of the Civil Code.
\end{abstract}

Keywords: Burden of proof, Defeasibility, Evidence facileness, Reform of civil procedure.

\title{
RÉSUMÉ
}

À partir de la perspective de la théorie du raisonnement juridique, cet article analyse l'article 1698 du code civil du Chili, dans lequel est énoncée la règle générale en matière de distribution de la charge de la preuve. Sur la base du cadre conceptuel de Frederick Schauer, selon lequel les règles prescriptives sont considérées comme des généralisations accompagnées de justifications sous-jacentes, cet article prétend démontrer que la distribution des charges, telle qu'elle est consignée dans l'article 1698, est susceptible de renversement. L'article expose des cas reconnus par la jurisprudence dans lesquels la généralisation de l'article 1698 ne sert pas à la justification sous-jacente et, par conséquent, la possibilité qu'ont les juges d'en renverser l'application. Les faits préventifs et modificatifs, d'une part, et, d'autre part, la facilité probante sont les principales hypothèses de possibilité de renversement de la distribution de la charge, telle qu'elle est présentée dans l'article 1698 du Code Civil.

Mots clés: Charge de la preuve, possibilité de renversement, facilité probante, réforme de la procédure civile.

\section{INTRODUCCIÓN}

La reforma al proceso civil en Chile propone introducir inversión judicial de la carga de la prueba en razón de "facilidad probatoria"'. Los acadé-

1 "Art. 294. Carga de la prueba. Corresponde la carga de probar los fundamentos de hecho contenidos en la norma jurídica a la parte cuya aplicación le beneficie, salvo que 
micos de Derecho Civil han criticado severamente esta propuesta (en adelante "Comentarios Civiles") ${ }^{2}$. Según ellos, la facilidad probatoria (o "carga dinámica") afecta la función de anticipar el futuro de los contratos porque quiebra la seguridad jurídica construida sobre las reglas civiles de carga de la prueba ${ }^{3}$. Los académicos de Derecho Procesal, a su turno, han replicado a estas críticas civiles ${ }^{4-5}$. Este debate abre la oportunidad para analizar desde distintas perspectivas la carga de la prueba y las repercusiones de la facilidad probatoria en la responsabilidad civil.

Este artículo trata acerca de ese tema en debate desde la perspectiva del razonamiento jurídico. En concreto, me enfocaré en el art. 1698 del $C C$ chileno que, como se sabe, distribuye de cierto modo la carga de la prueba. La pregunta que busco contestar acá es, si esa distribución de la carga del 1698 puede ser entendida como una norma derrotable o no. Que sea 'derrotable' significa que la regla puede dejar de ser aplicada en

una disposición legal expresa distribuya con criterios diferentes o de una manera diversa la carga de probar los hechos relevantes entre las partes. El tribunal podrá distribuir la carga de la prueba conforme a la disponibilidad y facilidad probatoria que posea cada una de las partes en el litigio lo que comunicará a ellas, con la debida antelación, para que asuman las consecuencias que les pueda generar la ausencia o insuficiencia de material probatorio que hayan debido aportar o no rendir la prueba correspondiente de que dispongan en su poder" (énfasis mío). "Proyecto de Ley... (2012), p. 104.

${ }^{2}$ Departamento de Derecho Privado de la Universidad de Chile (2012), 34 pp.

3 "La prueba de las obligaciones es, quizás, la materia que más reparos merece desde la perspectiva del derecho civil. El Proyecto recoge en el inciso $2^{\circ}$ del artículo 294 la regla de la carga probatoria dinámica, la que viene a alterar todo el sistema de prueba del Código Civil. Las reglas de prueba son, ante todo, normas de derecho sustantivo, que obedecen a imperativos de seguridad jurídica, siendo los contratos instrumentos para 'anticipar el futuro'. El establecimiento de la carga probatoria dinámica importaría significativas distorsiones en el sistema de contratos y de libre mercado, desde el momento que afectaría la función de previsión propia de los contratos; alteraría el sistema de los seguros y la actividad de las compañías aseguradoras, para las que es esencial la anticipación de los riesgos en los contratos sobre la base de las normas legales generales; atentaría contra el principio de la autonomía privada y de la intangibilidad de los contratos, ya que el juez podría ignorar aquella estipulación contractual en que los contratantes alteren la regla legal de la carga de la prueba de la culpa; perturbaría la teoría de los riesgos y las reglas del caso fortuito, de acuerdo a las cuales el deudor debe acreditar la pérdida de la cosa y el caso fortuito, respectivamente; mientras que, en materia extracontractual, afectaría el sistema de presunciones legales de culpa, que favorecen a las víctimas de los accidentes. En definitiva, la introducción de la carga probatoria dinámica descansa sobre la base de criterios altamente imprecisos, como lo son 'disponibilidad' y 'facilidad', lo que abre la puerta a la subjetividad del juez y a una vulneración de las reglas expresas y generales previstas en la ley, afectando con ello gravemente la seguridad jurídica”. VV.AA. (2012), p. 589.

\footnotetext{
${ }^{4}$ Tavolari (2012), pp. 355-362.

${ }^{5}$ Marín y Vidal (2012), pp. 379-382.
} 
sus propios términos en casos extraordinarios, indeterminables a priori. En esta monografía defenderé una tesis afirmativa, que el art. 1698 ha sido sistemáticamente derrotado, que la inversión judicial de la carga en razón de facilidad probatoria es una especie de derrotabilidad también.

La tesis de la derrotabilidad de las normas ha recibido gran atención de parte de los filósofos del Derecho en el último tiempo ${ }^{6}$. Los grandes debates en materia de argumentación jurídica o razonamiento legal giran en torno a temas como la única respuesta correcta, las lagunas del Derecho y la derrotabilidad. Escapa a las ambiciones de esta monografía intentar hacerse cargo por completo de ese extenso debate. Existen diversas posturas no sólo a favor sino que, también, en contra de la derrotabilidad. Aquí utilizaré el marco conceptual ofrecido por Frederick Schauer ${ }^{7-8}$, que es uno de los académicos más influyentes en esta área. Pero dejo constancia que este autor tiene sus propios críticos ${ }^{9}$ y también existen otros autores relevantes con concepciones distintas acerca de la derrotabilidad ${ }^{10}$.

Frederick Schauer entiende las reglas jurídicas como generalizaciones prescriptivas que poseen justificaciones subyacentes. Para manejar ese marco conceptual se requiere mayor aclaración acerca de qué se entiende por "generalizaciones prescriptivas" y "justificaciones subyacentes". Eso se hará posteriormente. Por ahora bastará con adelantar que, dentro de ese 16 marco, Frederick Schauer entiende la derrotabilidad como aquellos casos en que la aplicación de la generalización formulada en la regla, traiciona la justificación subyacente.

Este marco conceptual de Frederick Schauer puede ser aplicado para comprender las reglas de carga de la prueba. Esta monografía se avoca a hacer esa aplicación. El art. 1698 del $C C$, que distribuye la carga de la prueba, es también una generalización prescriptiva con su propia justificación subyacente. Y, además, existen casos de derrotabilidad en que la aplicación del 1698 traiciona la justificación subyacente a la distribución de las cargas probatorias.

Dentro de una cultura legalista, como la chilena, la teoría de la derrotabilidad de las normas suele ser resistida. Se denuncia un peligro grave a la seguridad jurídica si se aceptara. Se perdería previsibilidad si los jueces -so pretexto de honrar una supuesta justificación subyacente- puedan aplicar una regla a un caso que no estaba expresamente previsto en ella, o que dejen de aplicarla a pesar que el caso sí caiga dentro de su formu-

${ }^{6}$ Ferrer y Battista (eds.) (2012), 421 pp.

${ }^{7}$ Aquí combinaré dos de sus obras: Schauer (1998), pp. 223-240.

${ }^{8}$ Schauer (1991), 254 pp.

${ }^{9}$ Rodriguez (2012), pp. 89-107.

${ }^{10}$ Por ejemplo, Alchourrón (1996), pp. 331-348. Y en Chile, véase Atria, (2000), pp. 437-467. 
lación. Sugerir que las reglas del $C C$ sobre carga de la prueba pueden ser derrotadas -como sugiero en este artículo- despierta resistencias porque se sostiene que tras esas reglas está en juego buena parte de la función de previsibilidad y anticipación del futuro de los contratos.

Si bien la teoría de la derrotabilidad es resistida cuando es formulada en términos abstractos, lo cierto es que -en mi opinión- la regla del art. 1698 lleva siendo derrotada por la jurisprudencia y la doctrina desde hace ya varios años. Aquí demostraré cómo ha sido consistentemente derrotada la regla del art. 1698 en la jurisprudencia chilena, por una parte, y cómo la facilidad probatoria -que se pretende incluir con la Reforma Procesal Civil- continúa la línea de esa derrotabilidad, por la otra.

\section{El Razonamiento juRídico SEgún Frederick Schauer}

\section{Reglas como generalizaciones}

Es un lugar común diferenciar entre reglas descriptivas (ley de la gravedad) y prescriptivas $(C C)$. Pero ambas, sostiene Frederick Schauer, poseen en común ser generalizaciones, es decir, en vez de referir a casos particulares, refieren a "tipos" de casos. A diferencia de una observación individual -i.e. hoy (caso particular) está soleado- una regla descriptiva -i.e. los días de verano (tipo de casos) son soleados- es una generalización que buscar reportar una regularidad empírica ${ }^{11}$.

Las reglas prescriptivas son, en el mismo sentido, generalizaciones porque refieren a tipos de casos y no a particulares. Supongamos el clásico ejemplo de la señal en los andenes del tren que dibuja la silueta de un perro dentro de un círculo tachado en diagonal. Esa señal es una regla -i.e. los perros no están permitidos en el andén- que refiere a un tipo de casos ('los perros') y no a un caso particular ('el perro del vecino') ${ }^{12}$.

Ahora bien, las generalizaciones son selectivas. Al optar por uno u otro tipo abstracto ("los días de verano" en vez de "hoy día"; "los perros" en vez de "el perro del vecino") necesariamente se suprimen otras características que poseen los miembros que integran el tipo (si el día es impar o par en el calendario; si el perro es blanco o negro de pelaje). En las reglas descriptivas la selectividad de la generalización busca dar cuenta de la regularidad empírica que reporta. Es decir, se suprime la característica de si el día es par o impar en el calendario, porque eso sería una característica irrelevante para dar cuenta de cuándo los días suelen ser

${ }^{11}$ Schauer (1991), p. 17.

${ }^{12}$ Op. cit., p. 18. 
soleados. En cambio, la generalización se enfoca en la estación del año (otoño, invierto, primavera y verano) porque ésa sí es una característica relevante (en verano), para describir cuáles días suelen ser soleados ${ }^{13}$.

\section{Justificaciones subyacentes}

La generalización en una regla prescriptiva también es selectiva. La diferencia es que, en vez de reportar una regularidad empírica, la generalización prescriptiva busca servir una "justificación subyacente" ${ }^{14}$. En la señal de "no se permiten perros en el andén" la justificación subyacente sería evitar que la gente caiga en las vías del tren empujado por un perro en descontrol. La generalización prescriptiva suprime la característica del color del pelaje (negro, blanco, gris o café) porque eso no aumenta ni disminuye el riesgo de que gente caiga a la vía de tren, el color del pelaje es irrelevante para la justificación subyacente. En cambio, la generalización se enfoca en el tipo de mascota (aves, roedores, gatos y perros) porque eso sí es relevante para la justificación subyacente: los perros -a diferencia de los gatos, roedores y aves- sí tienen el tamaño y fuerza suficiente como para empujar a una persona.

Frederick Schauer enfatiza que las generalizaciones, además de selectivas, son probabilísticas ${ }^{15}$. Que "los días de verano son soleados" es bastante cierto a pesar de que, sabemos, hay algunos días de veranos en que no sale el Sol. Esto porque la regla descriptiva refleja una relación causal entre la estación del año, por una parte, y el clima, por la otra, que no es absoluta sino probable. La regla descriptiva, entonces, da cuenta de una causa que, probabilísticamente, es acertada para dar cuenta de la regularidad empírica que busca reportar.

Del mismo modo, las reglas prescriptivas también reflejan una relación causal probabilística, pero esta vez entre sus hechos operativos y su justificación subyacente ${ }^{16}$. En rigor, no existe una estricta relación causa-efecto entre "perros en el andén", por una parte, y "personas que caen en la vía del tren", por la otra. No siempre los perros empujan personas, pero es probabilísticamente correcto que su presencia en el andén (hecho operativo) aumenta el riesgo de que alguien se caiga en las vías (justificación subyacente).

De este modo Frederick Schauer entra en el debate entre Herbert Lionel Adolphus Hart ${ }^{17}$ y Lon Fuller ${ }^{18}$ y el clásico ejemplo de la regla que

\footnotetext{
${ }^{13}$ Schauer (1991), pp. 21-22.

${ }^{14}$ Op. cit., pp. 25-26.

${ }^{15}$ Op. cit., p. 27.

${ }^{16}$ Op. cit., pp. 28-29.

${ }^{17}$ Hart (1958), pp. 593-629.

${ }^{18}$ Fuller (1958), pp. 630-672.
} 
prohíbe vehículos en el parque. La regla así formulada excluye la entrada de automóviles. Pero bajo la noción de 'vehículos', ¿quedan excluidos de entrar al parque también los aviones, bicicletas o autitos de juguete? Herbert Lionel A. Hart sugiere que las reglas como ésta, tienen un texto abierto. Existe un núcleo duro de significado (automóviles) y al lado existen problemas de penumbra (aviones, bicicletas y autitos de juguete) con mayor discrecionalidad del juez para decidir si aplicar la regla o no. Lon Fuller contesta que la distinción entre núcleo y penumbra de una regla no tiene sentido, sino tomando en cuenta el propósito de la regla. Para demostrarlo, agrega el ejemplo de instalar en el parque un memorial de la Segunda Guerra Mundial consistente en un camión militar en perfecto estado de funcionamiento sobre un pedestal. Ese camión militar claramente cae dentro de lo que Herbert Lionel A. Hart llamó el núcleo duro de significado (es un automóvil), sin embargo, no sería razonable que un juez prohibiera la instalación del memorial en razón de la regla de "no-vehículos en el parque".

La respuesta de Lon Fuller es entendida por Frederick Schauer como una derrotabilidad ${ }^{19}$. La regla "no-vehículos en el parque" tiene una justificación subyacente, supongamos la preservación de la tranquilidad y silencio en el parque. En atención a esa justificación pueden ser fácilmente resueltos los casos de penumbra de Herbert Lionel A. HART. La bicicleta y el auto de juguete no alteran la tranquilidad y silencio, luego no quedan incluidos en la regla de "no-vehículos en el parque"; un avión, en cambio, sí altera la tranquilidad y silencio, luego sí cae dentro de la regla y debe ser excluido de entrar al parque. Y en el caso planteado por Lon Fuller del memorial de camión militar, a pesar de caer dentro del núcleo duro de significado, la razón por la cual la regla "no-vehículos en el parque" no debiera ser aplicada (se derrota), es porque no afecta la justificación subyacente a esa regla: el memorial no altera la tranquilidad ni el silencio del parque.

Frederick Schauer responde a Lon Fuller, agregando el caso del desfile de automóviles que se realiza un día en celebración del regreso de un vecino del barrio que fue a las olimpiadas y ganó seis medallas de oro ${ }^{20}$. Para aumentar dramatismo, agrega que el vecino ganador será acompañado por el popular Presidente de la República que, por una enfermedad de la que adolece desde la infancia, no puede caminar. ¿Debería el juez prohibir el desfile motorizado en razón de la regla "no-vehículos en el parque"? Intuitivamente creemos que no. Pero Herbert Lionel A. HART estaría forzado a prohibirlo porque los automóviles del desfile caen dentro

${ }^{19}$ Schauer (1991), p. 74.

${ }^{20}$ Op. cit., p. 75. 
del núcleo duro de significado de la regla de "vehículos". También Lon Fuller debería prohibirlo porque el desfile afecta la justificación subyacente de preservar la tranquilidad y silencio. Frederick Schauer, en cambio, está a favor de permitirlo. Según él, es acertado que la regla "no-vehículos..." tiene una justificación de primer orden en la tranquilidad y silencio del parque. Pero esa justificación también sirve a un propósito más profundo, una justificación de segundo orden: se protege la tranquilidad y silencio del parque (primer orden) para maximizar el bienestar de los vecinos (segundo orden). Entonces, en este caso, según Frederick Schauer, el desfile en automóviles la justificación de primer orden (tranquilidad y silencio), es derrotada por su propia justificación de segundo orden. Si bien el desfile irrumpe la tranquilidad y silencio (primer orden), el juez debe permitirlo porque favorece el disfrute de los vecinos (segundo orden) ${ }^{21}$.

Como se verá, esta interrelación entre la generalización prescriptiva con su justificación subyacente, por una parte, y entre la justificaciones de primer y segundo orden, por la otra, será la clave para entender después la derrotabilidad de la carga de la prueba. Es importante no perderla de vista.

\section{Derrotabilidad}

20 El debate entre Herbert Lionel A. Hart y Lon Fuller acerca de la textura abierta de las normas, sobre la relación entre Derecho y moral, permite a Frederick Schauer identificar la propiedad distintiva de la derrotabilidad de las normas:

"Un evento está, sin vaguedades, dentro de la formulación de la regla y aún así puede suceder que aplicar la regla a ese caso puede ser problemático. Y eso puede ser sólo cuando el evento, a pesar de estar sin vaguedades dentro de la formulación de la regla, estaba fuera del propósito de trasfondo a la regla (o viceversa). La propiedad distintiva de la derrotabilidad ha sido así expuesta [...] una regla es derrotable cuando su aplicación depende no sólo de la ocurrencia de un evento que cae dentro de la extensión lingüística de la regla, sino de que el evento caiga dentro del propósito de la regla también" ${ }^{22}$.

Según esta comprensión, los casos de derrotabilidad son aquellas hipótesis en que se da un descuadre entre la generalización de la regla (extensión lingüística) y su justificación subyacente (propósito de la regla). Estos descuadres se pueden dar en dos sentidos.

\footnotetext{
${ }^{21}$ Schauer (1991), pp. 75-76.

${ }^{22}$ Schauer (1998), p. 236.
} 
Se puede dar en un sentido infraincluyente y supraincluyente. O, bien, un caso particular que, aunque contenido en la formulación de la regla, no produce el efecto buscado por la justificación subyacente (supraincluyente) o, bien, un caso particular que, sin estar contenido en la formulación de la regla, sí produce el efecto buscado por la justificación subyacente (infraincluyente) ) $^{23-24}$.

Así, por ejemplo, supongamos una biblioteca en la cual hay una señal que prohíbe el uso de los aparatos de radio (esa señal es la formulación de la regla ${ }^{25}$. Podemos suponer que la razón de esa señal es evitar dentro de la biblioteca los ruidos que suelen emitir esos aparatos de radio y que molestan a quienes van a leer (justificación subyacente de esa regla). Sin embargo, la regla de esa señal no sería aplicable respecto del empleado de limpieza que trabaja antes del horario de atención a público. Él sí podría utilizar una radio mientras limpia porque, antes de la apertura al público, no está molestando a ningún lector (derrotabilidad supraincluyente). A su turno, si alguien intentara usar dentro de la biblioteca no una radio sino que un televisor, en rigor no quedaría cubierto por la regla formulada en la señal (que sólo se refiere a "aparatos de radio"). Pero la regla sí sería aplicable al uso de un televisor porque, al igual que las radios, también molestan a los lectores (derrotabilidad infraincluyente). En ambos casos -respecto del empleado de limpieza y del uso de televisor- la regla de la señal sería derrotable: no sería aplicable a un caso contenido en su formulación (empleado de limpieza) y sí sería aplicado a un caso no contenido en su formulación (uso del televisor).

Con todo, Frederick Schauer criticaría que la derrotabilidad fuera entendida como cualquier descuadre entre generalización y justificación, por mínimo que sea. Si la regla no será aplicada en todos los casos en que, si bien caen dentro de la formulación lingüística, contradicen su justificación (o viceversa, la regla será aplicada en todos los casos que cumplen su justificación a pesar de que no quepan dentro de su formulación lingüística), entonces, no se trataría de una toma de decisiones sobre la base de reglas, sino que sobre la base de la aplicación directa de su justificación ${ }^{26}$. Llevar la derrotabilidad a ese extremo volvería irrelevante el papel de las reglas porque su fuerza normativa se disuelve ${ }^{27}$.

${ }^{23}$ Shauer (1991), pp. 31-34.

${ }^{24}$ Son evidentes las similitudes entre la teoría de Common Law sobre derrotabilidad de las normas con la doctrina de Civil Law sobre 'interpretaciones restrictivas, extensivas y estrictas'.

${ }^{25}$ El ejemplo es de Ródenas (1983), pp. 20-21

${ }^{26}$ Schauer (1998), pp. 232-233.

${ }^{27}$ Op. cit., p. 237. 
No obstante, decidir conforme a reglas, continúa, sirve a propósitos valiosos como estabilidad, predictibilidad, distribución de autoridades, etc. Y esos propósitos se pueden cumplir sólo si la aplicación de reglas tienen cierto grado de resistencia frente a lo que, quien toma la decisión, cree que es correcto para este caso $^{28}$. Por eso, concluye, la derrota de las reglas debería reservarse para cuando se dan condiciones que no pueden ni necesitan ser especificadas con anticipación, condiciones que poseen un particular valor como contrapeso, valor particular que sí pueda ser especificado de modo anticipado y no esté sujeto, a su vez, a derrotabilidad ${ }^{29}$.

Concuerdo con Frederick Schauer que la decisión conforme a reglas debe resistir, en algún grado, desfases entre generalización y justificación. Pero discrepo que la derrotabilidad en razón de desfases infra o supraincluyentes vuelvan irrelevante decidir conforme a reglas. Las justificaciones de las reglas, si las formuláramos de modo directo como reglas, serían demasiado ambiguas para sustentar un sistema de decisiones sobre la base de ellas. En el caso del andén de la estación de trenes sería en extremo difícil aplicar una regla redactada directamente como su justificación ("no ingresar ninguna cosa que pueda causar que alguien caiga en la línea del tren”). Formular la regla en los términos exactos de su propia justificación traicionaría la propia justificación, porque volvería inoperante la aplicación de la regla que precisamente busca cumplirla: es imposible una toma de decisiones sobre la base de una regla que fuerza a discernir respecto de cada cosa si tiene o no el riesgo de empujar a alguien. Necesitamos de reglas, a pesar de que sean derrotables, porque formulan generalizaciones que sí son más operativas en la práctica: proteger a los pasajeros de caer a las vías del tren (justificación) es mucho más practicable si el que toma las decisiones se encarga de fiscalizar cuando hay "un perro", que si se le encargara identificar, ambiguamente, "toda cosa que..." pudiera causar ese riesgo. Del mismo modo, necesitamos la regla de "no-vehículos en el parque", a pesar de que sea derrotable cuando se descuadra con su justificación, porque su aplicación es mucho más manejable que la aplicación directa de la justificación. Es realista una regla que exija fiscalizar "vehículos" e impracticable otra que exija fiscalizar "todo aquello que afecta la tranquilidad y silencio" (justificación de primer orden) o peor aún, una regla que exigiera prohibir en el parque todo lo que no maximice el bienestar de los vecinos (justificación de segundo orden). La derrotabilidad en razón de discordancias con sus justificaciones subyacentes no vuelve inútiles las reglas, porque las reglas tienen algo que las justificaciones no tienen: ser suficientemente concretas como criterio de decisión operativo para el día a día.

${ }^{28}$ Schauer (1998), p. 239.

${ }^{29}$ Ibid. 


\section{El art. 1698 del Código Civil como generalización}

El $C C$ puede ser leído desde el marco conceptual de Frederick Schauer. $\mathrm{El}$ art. 1698 señala: "Incumbe probar las obligaciones o su extinción al que alega aquellas o ésta". La regla chilena es una redacción concentrada de la misma idea del art. 1315 del $C C$ francés:

"Aquel que reclama la ejecución de una obligación debe probarla. Recíprocamente, aquel que se pretende liberar, debe justificar el pago o el hecho que produjo la extinción de su obligación"30.

Ambas redacciones en realidad formulan dos reglas y cada una es una generalización distinta.

(A) Tras el "Incumbe probar..." hay una regla de carga del acreedordemandante y

(B) otra para el deudor-demandado.

Para el acreedor-demandante prescribe que A: "Incumbe probar las obligaciones [...] al que alega aquellas [...]". Dicho en otros términos, la primera regla dice: "Al que alega una obligación ('aquel que reclama la ejecución de la obligación'/acreedor-demandante) le incumbe probar la obligación". A su turno, para el deudor-demandado prescribe B: "Incumbe probar [...] su extinción al que alega [...] ésta". En otras palabras, dice la segunda regla: "Al que alega una extinción ('aquel que se pretende liberar' / deudor-demandado) le incumbe probar la extinción".

Sin embargo, se trata de dos reglas interdependientes. Que la carga de un determinado hecho corresponda a cierta parte significa, necesariamente, que la carga de ese mismo hecho no corresponde a la otra. Que la carga de la obligación corresponda "al que alega la obligación" significa, al mismo tiempo, que la carga de esa misma obligación no corresponde "al que alega la excepción" (y viceversa). La carga de uno es excluyente respecto de la del otro. Un mismo hecho no puede ser carga de ambas partes y un hecho no puede ser carga de ninguna de ellas.

Ambas reglas son generalizaciones, no se refieren a casos particulares sino a tipos ("el que alega aquéllas o ésta"). En consecuencia, son, en primer lugar, selectivas. La regla A, al atribuir la carga de probar la obligación "al que alega una obligación" (acreedor-demandante) selecciona enfocarse en unas características y no en otras. Omite, por ejemplo, si el que alega la obligación es una persona natural o jurídica, si son una o varias personas,

30 “Celui qui réclame l'exécution d'une obligation doit la prouver. Réciproquement, celui qui se prétend libéré, doit justifier le paiement ou le fait qui a produit l'extinction de son obligation". 
etc. Pero sobre todo omite -aquí está lo importante para discutir después sobre la facilidad probatoria- si acaso el que alega la obligación tiene en sus manos o no, o podría conseguir, la prueba para probar esa obligación. Viceversa, la regla B al atribuir la carga de la extinción "al que alega la extinción" se enfoca sólo en quién es el que alega el hecho y omite, asimismo, la característica de si el que alega tiene o no la prueba en sus manos.

$\mathrm{El}$ art. 1698 es, entonces, una generalización prescriptiva y, en consecuencia, sirve a una justificación subyacente, de primer y segundo orden. El apartado siguiente se aboca a identificar, de entre todos los candidatos, cuál es la justificación subyacente al art. 1698. Aclarar ese punto es crítico para determinar los espacios de derrotabilidad que dejaría o no la regla de carga de la prueba en la responsabilidad contractual.

\section{JUSTIFICACIÓN SUBYACENTE EN LA DISTRIBUCIÓN DE LA CARGA PROBATORIA}

La comprensión de la derrotabilidad de una regla depende, sobre todo, de cómo entendemos su justificación subyacente de primer y segundo orden. Por esa razón es importante detenernos a elucidar cuál sería la 24 justificación subyacente tras el art. 1698. Si es una u otra no da lo mismo porque será el contrapunto de la generalización. Si el art. 1698 tuviera tal o cual justificación tras de sí, importaría distintas aperturas, mayores o menores, a su derrotabilidad.

Existen varios criterios en juego: ilicitud, statu quo, normalidad, excepcionalidad, beneficio y facilidad. Con todo, estos criterios suelen no defenderse aisladamente, sino que los argumentos se construyen a partir de alguna combinación. Así, por ejemplo, el statu quo con la normalidad, la normalidad con la excepcionalidad, el beneficio con la facilidad, etc. A continuación, analizaré uno por uno para identificar qué criterio por sí solo, o cuál combinación, es el que mejor da cuenta de la justificaciones subyacentes tras las reglas generales de carga de la prueba del $C C$. El método para identificarlo es contrastar, uno por uno, qué candidato es capaz de explicar la mayor cantidad de situaciones reales de aplicación de la regla. Una vez identificado, me preguntaré acerca de cuál sería la justificación de segundo orden tras ese criterio.

\section{Ilicitud}

Un primer criterio que podría considerar es la ilicitud, es decir, corresponde probar los hechos ilícitos y los hechos lícitos se presumen verdaderos mientras no se pruebe lo contrario. Según él, no corresponde comenzar 
con la carga de probar el que defiende la licitud de un hecho, sino que comienza con la carga el que busca acreditar alguna ilicitud.

Este criterio de distribución es el que prima en materia penal. La presunción de inocencia es una presunción de que todos los hechos realizados no son delito (lícito) y, en consecuencia, la distribución de la carga se coloca primero sobre la acreditación de los que sí se consideran delitos (ilícito). Al imputado corresponde la carga de probar sólo en segundo lugar, cuando el ilícito ya ha sido acreditado para refutar esa prueba.

En materia civil el criterio de la ilicitud sirve, en algún grado, para explicar la mala fe, la nulidad y la responsabilidad por daños. Si considero la mala fe, los vicios de nulidad y los daños como ilícitos, entonces según este criterio no corresponde comenzar con la carga de probar sobre aquél que alega que tuvo buena fe, que el acto sí es válido o que no dañó a otros (actos lícitos). Se presume la buena fe, la validez civil y la ausencia de daño de un modo similar a como que se presume la inocencia penal y la ausencia de delito. La carga de la prueba recae primero, entonces, sobre quien denuncia la mala fe, el vicio de nulidad y los daños porque, según este criterio, ésos son los hechos ilícitos que parten con una presunción probatoria en contra que se debe superar.

Sin embargo, el criterio de la ilicitud no sirve de justificación subyacente de la distribución de la carga en la responsabilidad contractual civil en general. Según el criterio de la ilicitud, comenzaría con la carga aquél que alega un hecho ilícito. Empero, en la responsabilidad contractual, en virtud del art. 1698, comienza con la carga de probar el acreedor respecto de su contrato. Y, obviamente, un contrato no es un acto ilícito. Luego, no puede ser la ilicitud la justificación por la cual el art. 1698 le asigna primero la carga de probar el contrato al acreedor. A su turno, la carga de la prueba del demandado respecto de la extinción tampoco puede ser entendida como la carga de probar para refutar un hecho ilícito ya probado, porque el contrato que busca contradecir nunca fue ilícito desde un comienzo.

En suma, lo que hace de la ilicitud un buen criterio en materia penal es al mismo tiempo la razón por la cuál es débil como justificación subyacente en sede civil. En materia penal, por definición, siempre alguna de las partes del juicio estará alegando algún hecho ilícito, luego el criterio de ilicitud siempre será aplicable. Pero en sede civil es posible, y será usual que así suceda, que ambas partes estén alegando hechos igualmente lícitos.

\section{Statu quo}

El segundo criterio que se puede considerar es el statu quo, es decir, corresponde probar a aquél que busca romper una situación de hecho ya 
consolidada, al que busca cambiar el estado actual de cosas. Según él, no corresponde comenzar con la carga a aquél que busca mantenerse en la situación en que ahora se encuentra, sino que comienza con la carga el que busca sacarlo de esa situación. Este criterio es uno de los que combina la Sala Civil de la Corte Suprema, siguiendo a Arturo Alessandri, Manuel Somarriva y Antonio Vodanovic:

"Unánimemente se ha aceptado que ésta [la carga de probar] le corresponde rendirla al que sostiene una proposición contraria al estado normal u ordinario de las cosas, al que pretende destruir una situación adquirida. [...] Y esto no puede ser de otra manera precisamente a partir de lo que se ha dicho, esto es, que el actor pretende introducir un cambio en la situación existente, de manera que hasta que se pruebe lo contrario, se entenderá que el demandado debe conservar las ventajas de su situación" ${ }^{31-32}$ (énfasis mío).

El criterio del statu quo sirve bien para justificar que el que comienza con la carga de la prueba suele ser el demandante. La posición de demandante es, por definición, la de aquél que busca romper algún statu quo. El dueño que demanda de reivindicación busca romper el statu quo de que la cosa está actualmente en manos del poseedor-no-dueño; el acreedor de cumplimiento forzado quiere romper el statu quo de que el deudor está actualmente sin cumplir; la víctima que demanda indemnización de perjuicios busca romper el statu quo que los costos del accidente los está asumiendo actualmente ella y no el victimario, etc. Y como el demandante es el que busca romper el statu quo, entonces según este criterio es el demandante el que tiene la primera carga de probar.

Pero lo que hace útil al criterio del statu quo es lo que esconde su debilidad. Este criterio sirve de justificación subyacente de por qué el demandante tiene usualmente la carga al comienzo, pero falla en justificar por qué también existen presunciones probatorias que favorecen al mismo demandante. Bajo el criterio del statu quo no deberían haber presunciones a favor del demandante porque implicaría que el demandado quedaría con la carga de probar la mantención del statu quo que según el criterio debería estar exento de probar.

${ }^{31}$ Corte Suprema, rol 1096-2009 (25 de agosto de 2010). La Corte después reiteró en 86-09 (31 de agosto de 2010); 6331-2009 (26 de enero de 2011); 5234-09 (26 de enero de 2011); 6657-2009 (27 de enero de 2011); 7568-2009 (26 de marzo de 2011); 8792-2009 (25 de mayo de 2011); 6069-2009 (24 de junio de 2011).

32 Alessandri, Somarriva y Vodanovic (1991), pp. 410-411. 
Ése es el caso, primero, del art. 1547 que asigna la carga de probar la diligencia al que debió emplearla en las obligaciones de medio ${ }^{33}$. Claro, si la prueba correspondiera al que busca romper el statu quo entones sería el demandante el que debería probar el contrato y su incumplimiento. Mas, aquí la prueba del incumplimiento (el empleo de la diligencia) está cargada al deudor demandado, es decir, al que busca mantener el statu quo y no el que lo altera.

Lo mismo en las distintas presunciones de responsabilidad extracontractual del título xxxv del $C C$. En la presunción de responsabilidad por el hecho propio (art. 2314), el hecho ajeno (art. 2320) y por las cosas (arts. 2323, 2326, 2327) y del que arroja algo desde la altura (art. 2328 inciso primero) será el demandado de indemnización de perjuicios -es decir, el que busca mantener el statu quo y no el demandante que pretende cambiarlo- el cargado con la prueba de la culpa.

En suma, el criterio del statu quo es más explicativo que el de la ilicitud. Sirve para justificar por qué tenemos la regla general que la carga de probar corresponde primero al demandante. Pero falla en aportar un criterio que logre justificar las excepciones que también existen, que liberan al demandante de ciertas cargas y se la asignan al demandado que busca, por el contrario, preservar el statu quo.

\section{Normalidad}

El tercer criterio es la normalidad, es decir, corresponde probar aquel hecho que se desvía del comportamiento normal, al que busca probar una anormalidad. Según él, no corresponde asignar la carga a quien reclama a su favor el hecho que normalmente sucede. La situación anormal, que es la que requiere prueba, es un evento que ocurre en una proporción menor (infrecuente) por oposición a otro hecho que es el que ocurre en la gran mayoría de los casos y que, por eso, es considerado lo 'normal' o frecuente. Así, por ejemplo, lo normal es que los días de verano sean soleados y que llueva es la anormalidad a probar. Este criterio lo combinan tanto la jurisprudencia de la Corte Suprema como los "Comentarios al proyecto del nuevo Código Procesal Civil":

Corte Suprema: "Unánimemente se ha aceptado que ésta [la carga de probar] le corresponde rendirla al que sostiene una proposición contraria al estado normal u ordinario de las cosas [...]" 34 .

${ }^{33}$ Aquí sigo la interpretación de PiZARro (2008), pp. 255-265. Para una interpretación distinta véase VIDAL (2010), p. 575.

${ }^{34}$ Corte Suprema, rol 1096-2009 (25 de agosto de 2010). La Corte después reiteró, literalmente, el argumento también en 86-09 (31 de agosto de 2010); 6331-2009 (26 de enero 
Comentarios al proyecto del nuevo Código Procesal Civil: "El artículo 1698 establece que deberá probar las obligaciones el que alega la existencia o la extinción de éstas. Lo anterior, resulta razonable y justo ya que lo normal será que las personas no estén obligadas [...]"35 (en ambos énfasis mío).

De un modo similar al statu quo, el criterio de la normalidad justifica bastante bien por qué la carga de la prueba se asigna primero al demandante. En el día a día de nuestras vidas -en la situación prototípica de una persona natural- el estar en una situación de obligación civil para con otro es lo infrecuente ${ }^{36}$. Es decir, en la responsabilidad contractual lo normal es que no estemos sujetos a vínculos contractuales y, en consecuencia, en una acción de cumplimiento forzado es el demandante el cargado de probar la anormalidad de estar contratados. En la responsabilidad extracontractual lo normal es que no nos causemos daños unos a otros y, en consecuencia, en una acción de indemnización de perjuicios el demandante es el cargado de probar que un daño se causó.

El criterio de la normalidad, si bien es fuerte para justificar por qué el demandante tiene su carga, es débil para justificar por qué el demandando también tiene sus propias cargas de probar. En la responsabilidad contractual, el demandante-acreedor tiene la carga de probar la existencia del contrato porque estar contratados es lo anormal; a su turno, el art. 1698 asigna la carga de probar la extinción de la obligación al demandadodeudor. ¿Pero que las obligaciones estén extintas es algo anormal?

Si me enfoco en aquellos modos de extinguir algo exóticos -como la novación o la compensación- sólo ahí podríamos sostener que la extinción es una anormalidad. Ciertamente, es infrecuente que exista un vicio de nulidad, lo normal es que los contratos sean válidos, se celebren de buena fe entre capaces, sin error, dolo ni objeto o causa ilícita. El caso fortuito también es, pero por definición, una anormalidad: una hipótesis de caso fortuito que no fuera un evento infrecuente no sería, desde un comienzo, caso "fortuito".

Pero, insisto, hasta el momento me he enfocado sólo en los modos exóticos de extinguir. ¿Pero qué tanto cambia el encuadre si, a la inversa, incluyo también el modo de extinguir más habitual de todos: solución o pago efectivo?

de 2011); 5234-09 (26 de enero de 2011); 6657-2009 (27 de enero de 2011); 7568-2009 (26 de marzo de 2011); 8792-2009 (25 de mayo de 2011); 6069-2009 (24 de junio de 2011).

${ }^{35}$ Departamento de Derecho Privado de la Universidad de Chile (2012), p. 16.

36 "Probablemente" porque el día a día en ciertas situaciones, como en un banco, lo normal sí es estar obligado civilmente. 
Claro, si tengo en mente las situaciones reales de litigio, no es común que se esgrima el pago efectivo, puro y simple, como defensa. Los juicios suelen versar sobre hipótesis más complejas: caso fortuito, incumplimiento imperfecto, nulidad. No obstante, las situaciones de litigio -sobre las cuales suele desarrollarse la dogmática de carga de la prueba- no son una muestra representativa. Si el pago efectivo no suele ser esgrimido en situaciones reales de litigio no es porque el pago sea anormal o infrecuente en el tráfico jurídico fuera de los tribunales. No, son pocos los juicios en que se esgrime un pago efectivo puro y simple, porque ese tipo de casos suelen no llegar a judicializarse. Un acreedor al que le pagaron in natura la obligación, en tiempo y forma, se abstendrá de demandar porque, aunque demandara, no tendrá mucho más que conseguir por sobre los costos de litigar. $\mathrm{O}$, visto de otro modo, la situación imaginable en que una demanda tiene las menores probabilidades de éxito es, precisamente, cuando el deudor está en buen pie de esgrimir la defensa de pago efectivo; y eso inhibe a cualquier litigante estratégico de demandar desde un comienzo.

Entonces el criterio de la normalidad fracasa en justificar por qué según el art. 1698 el demandado tiene la carga de la extinción de la obligación, incluido el pago. Lo usual, lo frecuente es que los que celebran contratos los extingan por pago efectivo. El tráfico jurídico es posible sólo si los incumplimientos se mantienen como anomalías infrecuentes, mientras que en la gran mayoría de los casos los contratos se cumplen pura y simplemente. En la situación prototípica de una persona natural -en el día a día de nuestras vidas- lo normal es que si nos obligamos, paguemos. Si no fuera así, y lo "normal" es que los contratos se quedaran sin cumplir (sin extinguirse por pago efectivo), entonces no habría tráfico jurídico. Los bancos participan del negocio de colocar y recuperar créditos porque en la gran mayoría de los casos los deudores devuelven lo prestado más la tasa de interés pactada, por regla general, extinguen por pago efectivo el mutuo de dinero al que se obligaron. Si que los deudores no devolvieran el dinero fuera una situación infrecuente -si la extinción de una obligación por pago efectivo fuera verdaderamente una anormalidad- entonces los bancos no participarían del negocio de prestar dinero desde un comienzo.

En suma, el criterio de la normalidad es aún más justificativo que el del statu quo. El contrato, la nulidad y el caso fortuito son anormalidades infrecuentes y corresponde probarlas, es cierto, pero el pago efectivo mismo sí es una situación normal -de hecho la más normal de todas en el tráfico jurídico- que según el criterio de la normalidad no correspondería probar. Si la normalidad fuera la justificación subyacente a la distribución de la carga de la prueba en el $C C$, entonces el deudor no debería estar cargado de probar algo tan normal como el pago. Pero ese no es el caso. $\mathrm{El}$ art. 1698 le asigna la carga de probar las extinciones de la obligación, 
incluido el pago, al deudor-demandado. Luego, no puede ser la normalidad la justificación subyacente por la cual se lo asigna el código, el criterio necesariamente debe ser otro.

\section{Excepcionalidad}

Un cuarto criterio es la excepcionalidad, es decir, las reglas generales de distribución les asignan la carga a quien alega una "excepción” en alguno de sus sentidos. En los Comentarios al proyecto del nuevo Código Procesal Civil, junto a la normalidad, se combina el criterio de excepcionalidad. El art. 1698 -como las otras reglas de carga probatoria dispersas en el Código, sostienen- sería una regla general que distribuye la carga según quién alega una "excepción". El argumento es formulado en los siguientes términos:

"El artículo 1698 establece que deberá probar las obligaciones el que alega la existencia o la extinción de éstas. Lo anterior, resulta razonable y justo ya que lo normal será que las personas no estén obligadas. La obligación es una excepción. Por ello, el sistema de derecho civil hace recaer la prueba en quien quiere alegar la excepción, es decir, alegar que el otro está obligado. Asimismo, una vez que se está obligado, el derecho hace recaer la prueba en quien quiere alegar que dicha obligación se extinguió, es decir, en quien alega la situación excepcional que existiendo una obligación ésta ha dejado de existir"37 (cursivas mías).

Para comprender este argumento es necesario desambiguar el uso que hicieron del término 'excepción', que tiene tres significados: descriptivo, normativo y procesal. Descriptivamente, la 'excepción' equivale al criterio de la normalidad abordado en el punto anterior. La excepción-descriptiva es la situación anormal, es decir, un evento infrecuente que ocurre en un una proporción considerablemente menor a la situación normal. Del punto de vista normativo, en cambio, 'excepción' alude a una regla de competencias más específicas que contempla una consecuencia jurídica distinta a las de otra regla de competencias más amplias. Así, por ejemplo, el tribunal competente para conocer de las demandas civiles es el del domicilio del demandado, por regla general, y en los juicios de alimentos podrá ser el del domicilio del alimentario, por excepción-normativa. Procesalmente, por último, 'excepción' es un término que alude a las defensas del demandado en juicio, por oposición a la acción o pretensión del demandante. Así, por ejemplo, el demandante interpone una acción de reivindicación y el demandado se defiende con una excepción-procesal de cosa juzgada.

37 Departamento de Derecho Privado de la Universidad de Chile (2012), p. 16. 
La relación entre estos tres significados es contingente. El hecho gobernado por una regla especial (excepción-normativa) puede ser o no un evento que sucede en una pequeña porción de casos (excepción-descriptiva). Un demandado se puede defender (excepción-procesal) alegando a su favor tanto reglas generales como especiales (excepción-normativa), alegando un hecho frecuente o uno infrecuente (excepción-descriptiva). Aclarar esto es importante porque la tesis central del párrafo citado -la que devela, según los Comentarios Civiles, el criterio que sería la justificación subyacente a la distribución de la carga de probar en el $C C$ - es formulada con esa triple ambigüedad: "el sistema de derecho civil hace recaer la prueba en quien quiere alegar la excepción" (¿descriptiva, normativa o procesal?).

Cuando los Comentarios al proyecto del nuevo Código Procesal Civil se dedican a explicar la primera parte del art. 1698 ("incumbe probar la probar las obligaciones [...] al que alega aquellas...”), ¿a cuál de estos tres significados se refiere? Con la existencia de una obligación probablemente sí sea una excepción en un sentido descriptivo; lo puede ser en uno normativo; $y$, sin duda, no lo es en un sentido procesal.

Pareciera ser en sentido descriptivo (como anormalidad o infrecuencia) que los Comentarios al proyecto del nuevo Código Procesal Civil utilizan el término 'excepción' aquí: "lo normal será que las personas no estén obligadas. La obligación es una excepción” [léase, infrecuente]. Sin embargo, como vimos en el apartado anterior, entender la distribución de la carga como normalidad está destinado al fracaso cuando se intente explicar después por qué la carga de la prueba del pago corresponde el deudor, siendo que pagar es normal. En consecuencia, la mejor lectura que podemos hacer del criterio de la excepción es reconducirlo a uno de los dos sentido restantes, normativo o procesal.

Desde la perspectiva procesal, que el art. 1698 asigne al acreedor la carga de la existencia de la obligación no es una excepción, porque la existencia de la obligación suele ser esgrimida en juicio, por el contrario, más como un hecho de la acción del demandante que como excepción del demandado ${ }^{38}$.

En un sentido normativo, ahora, que al acreedor corresponda probar la existencia de la obligación, podría llegar a ser considerado como la prueba de una excepción-normativa sólo si encontramos alguna regla general que contemple una consecuencia jurídica a la cual, la existencia de la obligación, como regla especial, se oponga. Una alternativa es atender al

${ }^{38}$ La existencia de una obligación sólo será parte de la defensa del demandado (excepción-procesal) en casos puntuales, como el que alega la compensación como modo de extinguir en respuesta a la acción de cumplimiento forzado en su contra. 
art. 1437. En efecto, ese artículo -al definir taxativamente cuándo existirá una obligación civil válida (fuentes) - podría suponer tras de sí otra regla negativa. Tras el art. 1437 subyace la regla general de que no hay obligaciones, sino sólo en las hipótesis ahí señaladas (excepción-normativa) ${ }^{39}$. En consecuencia, el acreedor, al buscar demostrar que sí existe un contrato, está cargado de probar porque el contrato es una excepción-normativa que se opone a una consecuencia jurídica; pero no a la del art. 1437 directamente, sino a la de regla general negativa que subyace en forma implícita tras ese artículo, de que las obligaciones no existen. Con todo, aceptar que el contrato efectivamente es la prueba de una excepción-normativa, implica un supuesto demasiado frágil: que vamos a aceptar como reglas generales -para identificar, por contraste, dónde hay excepciones con carga de probar- reglas que, en rigor, no están consagradas en ninguna parte del Código en sus propios términos.

Para explicar la segunda parte del art. 1698 ("incumbe probar [...] su extinción al que alega [...] ésta") los Comentarios al proyecto del nuevo Código Procesal Civil extrapolan la mismo criterio de que el Derecho Civil asigna la carga a quién alega una "excepción” y cabe preguntarse, una vez más, a cuál de los tres significados ahora se refiere. Pero en la extinción de una obligación -a la inversa de su existencia-, sin duda no es una excepción en un sentido descriptivo como se demostró en el apartado anterior (el pago es algo normal, no es una excepción-descriptiva). En consecuencia, el criterio de la excepcionalidad respecto de la carga de la extinción para el deudor, de nuevo, sólo resta ser leído en un sentido normativo y procesal.

Claro, desde un punto de vista estrictamente procesal es bastante correcto afirmar que la extinción de una obligación es también una excepción-procesal (entre otras como la cosa juzgada, la falta de jurisdicción o legitimización para obrar) y también es cierto que el demandado que opta por defenderse alegando una de estas extinción-excepción-procesal, le corresponderá probarla.

En su sentido normativo, ahora, ¿̇la extinción también puede ser una excepción? Para que sea cierto, recordemos, hay que encontrar alguna regla general con una consecuencia jurídica a la cual la extinción -entendida como regla especial- se opone. Encontrar eso aquí es demasiado difícil. Si tenemos en mente la extinción de la obligación por declaración de nulidad o la convención que la da por nula, sí podemos ver una verdadera

${ }^{39}$ Con todo, el art. 1437 deja de ser visto como una excepción-normativa si lo contrastamos con el régimen de nulidad. Claro, así visto el art. 1437 define no la excepción, sino la regla general de la validez de las obligaciones, y son el resto de los vicios del acto jurídico las verdaderas excepciones-normativas. 
excepción-normativa porque con ellas se entiende que la obligación en efecto nunca existió y eso sería propiamente oponerse a la consecuencia jurídica del art. 1437, que define cuándo existen obligaciones. Pero con los demás modos de extinguir, las consecuencias jurídicas son distintas. Que se dé confusión o novación, por ejemplo, no significa que nunca existió una obligación válida -en rigor, no se oponen a la consecuencia jurídica del 1437- sino que ésta se extinguió, de ahí en adelante, de un modo distinto al cumplimiento. En consecuencia, es demasiado difícil hacer pasar la prueba de los modos de extinguir las obligaciones como la prueba de verdaderas excepciones-normativas no porque no hayamos encontrado alguna regla general con qué contrastarla, como el art. 1437 - pasando por alto que tres párrafos más arriba el mismo artículo lo estábamos considerando, a favor de los Comentarios al proyecto del nuevo Código Procesal Civil, como una regla especial y no una general- sino porque la mayoría de los modos de extinguir (pago, novación, compensación, confusión, transacción, prescripción) en rigor no se oponen a la consecuencia jurídica de esa regla general.

De este modo queda refutado el criterio de la excepcionalidad porque no logra ser consistente si se desambigua. Primero se descartó que el término 'excepción' pueda utilizarse en un sentido descriptivo por las mismas razones que se refutó el criterio de la normalidad en el apartado anterior. Pero aun respecto de los dos sentidos restantes, normativo y procesal, el criterio de la excepcionalidad es inconsistente porque sólo puede ser correcto si se utiliza el término 'excepción' en sentidos distintos, en uno respecto de la existencia de la obligación y en otro respecto de su extinción. Así, sería correcto si se refiriera a que la existencia de la obligación como una excepción en un sentido normativo y se refiriera a la extinción como excepción en un sentido procesal. No obstante, la excepcionalidad no logra ser correcta si el término 'excepción' es utilizado en el mismo sentido en ambos casos. Si se refiriera a excepción-procesal (defensa) entonces sería, como vimos, probablemente correcta respecto de la extinción, pero incorrecta respecto de la existencia de la obligación. Y si se refiriera a excepción-normativa (regla especial) puede ser cierta respecto de la existencia de la obligación, pero no lo es respecto de su extinción. Porque no logra ser consistente, entonces, no cabe sino descartar también el criterio de la excepcionalidad como justificación subyacente.

\section{Beneficio}

Un quinto criterio es el beneficio o interés, es decir, que las reglas generales distribuyen la carga según a quien favorece o perjudica la consecuencia 
jurídica atada a ese hecho ${ }^{40}$. Según él, corresponde probar determinado hecho, no a quien perjudica, sino a quien le favorece probarlo. Bajo este criterio, entonces, el art. 1698 asigna la carga de probar las obligaciones o su extinción "al que alega" aquéllas o ésta, porque asume, razonablemente, que el que lo alega lo hace porque le favorece. Si no le favoreciera entonces el litigante estratégico no lo alegaría, guardaría silencio.

Así, la existencia de la obligación es carga del acreedor, no porque la obligación sea necesariamente un quiebre al statu quo, a un patrón normal o porque se está aplicando alguna excepción contra otra regla más amplia. No, el art. 1698 se le asigna al acreedor porque es él el beneficiado con que quede probado en juicio que la obligación existe. Al contrario, el Código no asigna la carga de probar la existencia de la obligación al deudor porque a él le perjudica que se pruebe en juicio que existe una obligación contra él.

A su turno, se asigna la carga de probar la extinción de la obligación al deudor, no porque la extinción sea anormal o excepcional. El Código se la asigna al deudor -incluido el pago, a pesar de que sea frecuente- porque es él el que se beneficia con que quede probado en juicio el modo de extinguir. Al contrario, el Código no le asigna la carga de probar la extinción al acreedor porque a él le perjudica que se pruebe que la obligación que 34 exige estaba extinta.

Como se ve, mientras los criterios de la ilicitud, el statu quo y la excepcionalidad sólo lograban dar cuenta de una de las dos partes del art. 1698, el del beneficio logra dar cuenta de ambas al mismo tiempo. Incluso, por sobre el criterio de la normalidad, el beneficio logra ser una mejor justificación subyacente porque logra explicar por qué el deudor tiene la carga de todas las extinciones, incluido el pago que según la normalidad debiera quedar fuera.

Pero no sólo respecto de la regla general del art. 1698 sino, también, de las otras reglas dispersas en el Código. Cuando el art. 1547 asigna la prueba del caso fortuito al que lo alega, no lo hace porque tenga ahí un criterio distinto al del beneficio. Fue necesario decirlo en el art. 1547 porque el caso fortuito, en rigor, no quedaba cubierto por ninguno de los modos de extinguir que contempla el art. 1547, que es al que refiere el 1698. En consecuencia, el inciso tercero del art. 1547, en vez de una excepción, está reafirmando que el criterio de distribución de carga es el beneficio, y que eso se aplica también al caso fortuito a pesar de que no

${ }^{40} \mathrm{El}$ proyecto de ley que establece un nuevo $C P C$ formula este criterio expresamente como regla. Recordemos: "Art. 294. Carga de la prueba. Corresponde la carga de probar los fundamentos de hecho contenidos en la norma jurídica a la parte cuya aplicación le beneficie [...]". 
sea propiamente un modo de extinguir, porque a quien beneficia es al deudor que lo alegará.

En suma, el criterio del beneficio es el mejor candidato como justificación subyacente de primer orden a las reglas generales de distribución del $C C$ por sobre el statu quo, la normalidad y la excepción, porque justifica ambas partes del art. 1698, incluido el pago normal, como también las excepciones dispersas. Curiosamente el criterio del beneficio, si bien es la mejor justificación subyacente a las reglas de distribución, al mismo tiempo las vuelve inútiles. Advertirle al acreedor que tiene la carga de probar el contrato es inútil porque, como le beneficia que la obligación exista, él tendrá un incentivo autónomo para probarlo, haya o no una regla que se lo encargue. Lo mismo respecto del deudor, él tendrá incentivos para probar la extinción de la obligación, tenga o no sobre sí una regla que se lo ordene, porque le beneficia.

\section{Justificación de segundo orden: incentivos para probar}

Aclarado, entonces, que el beneficio es la justificación de primer orden, cabe preguntarse ahora, ¿cuál sería su justificación de segundo orden? $\mathrm{El}$ art. 1698 distribuye la carga del modo que lo hace para asignársela a quien le beneficia (primer orden). Pero para, ¿qué el Código distribuye a partir del beneficio la carga (segundo orden)?

Las reglas generales de carga probatoria pueden ser vistas como incentivos. Y lo que busca el $C C$ con el criterio del beneficio es elaborar un sistema inteligente de distribución de incentivos que asigne la carga de probar, de un modo tal, que los hechos se prueben. Ésa es, en mi opinión, su justificación de segundo orden. Para lograr que los incentivos se dirijan hacia que los hechos se prueben (justificación de segundo orden), este sistema asigna la carga de probar determinado hecho a aquella parte que más le interesa que ese hecho sí quede probado (beneficio, justificación de primer orden). A la inversa, el Código busca evitar que la carga de un hecho termine cayendo en manos de quién no está interesado en que ese hecho se pruebe, porque eso no lograría la meta final de que se prueben los hechos en juicio.

Según la justificación de primer orden (beneficio), el art. 1698 le asigna la carga de la obligación al acreedor porque es él el favorecido con que quede probado en juicio que la obligación existe. Según la justificación de segundo orden (incentivos para que los hechos se prueben), el criterio del beneficio le asigna esa carga al acreedor porque, como lo favorece, será él el más incentivado en reunir, conservar y presentar diligentemente al tribunal la evidencia sobre la existencia de la obligación que reclama. 
Al contrario, el criterio del beneficio no asigna la carga de probar la existencia de la obligación al deudor porque -como a él le perjudica que se pruebe en juicio que existe una obligación contra él- tendrá incentivos para ser, por el contrario, negligente o doloso en la reunión, conservación y presentación de esa evidencia.

A su turno, según la justificación de primer orden, el Código la asigna la carga de la extinción al deudor porque es a él al que favorece que quede probado en juicio el modo de extinguir. Según la justificación de segundo orden, el criterio del beneficio le asigna esa carga al deudor porque, como le favorece, será él más incentivado en reunir, conservar y presentar de forma diligente al tribunal la evidencia sobre la extinción. $\mathrm{Al}$ contrario, el criterio del beneficio no le asigna la carga de probar la extinción al acreedor porque -como a él le perjudica que se pruebe que la obligación que reclama se extinguió- tendrá incentivos para frustrar la prueba de ese hecho.

En suma, el criterio del beneficio es el mejor candidato como justificación subyacente de primer orden para las reglas generales de distribución del $C C$, por sobre el statu quo, la normalidad y la excepción. Y la justificación de segundo orden del criterio del beneficio, es que con él se logra que los hechos queden finalmente probados en juicio porque construye un entramado de incentivos para que la carga de la prueba quede en cada uno de los actores antagónicos que tienen mayor interés en ser diligentes con la prueba de esos hechos.

\section{DerrotabilidAD DEL ART. 1698 DEL Código CIVIL}

Como se vio, una regla puede ser derrotada cuando se da un descuadre relevante entre la generalización que utiliza versus la justificación que le subyace. Ahí, la regla se derrota porque traiciona su justificación. Ese descuadre puede ser infra o supraincluyente, dependiendo de si el caso cumple la justificación, pero no cae dentro de la generalización (derrotabilidad infraincluyente) o si, cayendo dentro de la generalización, no cumple su justificación (derrotabilidad supraincluyente).

Con las reglas de carga de la prueba del $C C$ también se pueden dar casos que descuadran generalización con justificación, tanto infra como supraincluyentes, que justifican su derrota. Para encontrar jurisprudencia sobre derrotabilidad infraincluyente del art. 1698 del $C C$ se necesita identificar casos que cumplen con su justificación (distribución según el beneficio) pero que no caen dentro de las dos generalizaciones que formula. A encontrar ese tipo de casos se avoca el título siguiente. Mientras 
que para encontrar jurisprudencia sobre derrotabilidad supraincluyente se necesita identificar casos que caen dentro de la generalización del art. 1698, pero que no cumplen su justificación. A encontrarlos se abocará el título subsiguiente.

\section{Derrotabilidad infraincluyente: Hechos impeditivos y modificativos}

La redacción del art. 1698 sólo hacía referencia a las obligaciones y a su extinción (no a otras categorías) porque estaba siguiendo de cerca, como vimos, el art. 1315 del $C C$ francés, que también se limitaba a esas dos categorías. Sin embargo, el debate sobre los hechos impeditivos (Giusseppe Chiovenda ${ }^{41}$, Dieter Leipold ${ }^{42}$ ) demostró que la regla -ya sea en la redacción francesa o en la versión chilena abreviada- así formulada es insuficiente.

Según la regla original, al acreedor corresponde la carga de la obligación, supongamos, el contrato. Mas la existencia de un contrato requiere, además de su fuente propiamente tal (i.e. el documento en que consta un acuerdo de voluntades), del cumplimiento de otros requisitos como la seriedad. Si bien la seriedad es parte de la existencia de la obligación (y según el art. 1698 correspondería su carga al acreedor), existe un consenso que sería irracional exigir que cada vez que un acreedor-demandante esgrime un contrato, deba rendir prueba adicional acerca de su seriedad. En consecuencia, será el deudor-demandado el encargado de probar la falta de seriedad a pesar que se trata de un hecho negativo.

Es así como surge la tercera categoría-después de los constitutivos y extintivos-de hechos impeditivos, entendidos como los hechos negativos de faltar algún requisito concurrente a la existencia de la obligación ${ }^{43}$. A los hechos impeditivos se sumó la cuarta categoría de los hechos modificatorios, entendido como aquéllos que presuponen la existencia válida de la obligación, pero alteran sus efectos normales. El ejemplo de hecho modificativo es la excepción de contrato no cumplido (mora purga la mora), que no extingue la obligación que se exige contra el demandado, pero posterga su exigibilidad hasta el cumplimiento recíproco.

${ }^{41}$ Chiovenda (2005), pp. 33-35.

${ }^{42}$ Sobre este debate véase PRÜTTING (2010), p. 459.

${ }^{43}$ Hay casos de la jurisprudencia chilena que han aplicado la doctrina del hecho impeditivo, como la Corte Apelaciones en rol 2938-2010 (18 de marzo de 2010). Ahí la existencia de otros bienes fue considerado un hecho impeditivo de cargo del acreedor hipotecario (demandante) contra el tercerista de prelación. 
Los países con Códigos Civiles más recientes, como Brasil ${ }^{44}$ o Italia ${ }^{45}$, sí formulan la regla de carga sobre la base de estas cuatro categorías. A la inversa, en los países con mayor resistencia a reformar sus Códigos Civiles por su tradición, como Francia y Chile, en vez de motivar un cambio legislativo en la formulación de la regla original de carga -para incluir esta tercera y cuarta categoría- la doctrina de los hechos impeditivos y modificativos terminó siendo abiertamente tolerada por la jurisprudencia, haciendo caso omiso que, en rigor, la regla original del Código no la contemplaba.

Si se traduce la jurisprudencia de los hechos impeditivos y modificativos en los términos de Frederick Schauer, se notará que es, a final de cuentas, una derrotabilidad. Al igual que el caso del televisor en la biblioteca, los hechos impeditivos y modificatorios no caen dentro de la generalización de la regla del art. 1698, pero cumplen su justificación. Los hechos impeditivos y modificatorios no son, en rigor, "extinciones". Pero a pesar de que no lo son -al igual que un televisor no es un "aparato de radio"- aun así le asignamos la carga de la prueba de ambos al deudor, porque es a él a quien beneficia probarlos (justificación subyacente). Se asigna al deudor la carga de la prueba respecto a la modificación o el impedimento de la obligación, a pesar de que el art. 1698 no lo dice. Así la justificación subyacente del Código continúa distribuyendo los incentivos para que los hechos sí se prueben (justificación de segundo orden), asignando la carga a quien tiene más interés o mayor beneficio (justificación de primer orden) en que se pruebe el hecho que modifica el efecto de la obligación o impide su existencia (a saber: el deudor) y no asignándosela al acreedor, que es quien tiene, a la inversa, el interés de que ello no se pruebe, traicionando la justificación de primer y segundo orden. Por las mismas razones que tampoco se permite entrar el televisor a la biblioteca (rompe el silencio de los lectores al igual que los "aparatos de radio" que contemplaba la regla), es que la carga de los hechos impeditivos y modificatorios se le asigna al deudor: se trata de derrotabilidades infraincluyentes.

La jurisprudencia que fuerza introducir las cuatro categorías de hechos dentro de la lectura que se hace del art. 1698, que en rigor sólo contempla dos, es abundante y literalmente copiada fallo tras fallo:

${ }^{44}$ El Código Procesal Civil brasileño de 1973 señala en su art. 333: "O ônus da prova incumbe: I - ao autor, quanto ao fato constitutivo do seu direito; II - ao réu, quanto à existência de fato impeditivo, modificativo ou extintivo do direito do autor". Sobre la carga de la prueba en Brasil véase Marinoni y Arenhart (2009), pp. 165-168.

${ }^{45}$ El Código Civilitaliano de 1942 señala en su art. 2967: "Onere della prova. Chi vuol far valere un diritto in giudizio (Codice di Procedura Civile. 163) deve provare i fatti che ne costituiscono il fondamento (Codice di Procedura Civile 115). Chi eccepisce l'inefficacia di tali fatti ovvero eccepisce che il diritto si è modificato o estinto deve provare i fatti su cui l'eccezione si fonda". Sobre la carga de la prueba en Italia véase Comoglio, Corrado e TARUfFo (1995), pp. 438-441. 
"Así, el demandante deberá probar los hechos constitutivos, que son aquéllos que producen el nacimiento de un derecho o de una situación jurídica que antes no existía y que son el fundamento de su demanda, encontrándose el demandado, por su parte, en la necesidad de probar los hechos extintivos, impeditivos o modificativos capaces de justificar el rechazo de la demanda del actor. Lo anterior ha quedado plasmado en la regla contenida en el artículo 1698 del Código Civil, que en su inciso primero dispone: 'Incumbe probar las obligaciones o su extinción al que alega aquéllas o ésta"' ${ }^{46}$ (énfasis mío)

De este modo queda demostrado que el art. 1698 del $C C$ ha sido, y seguirá siendo, sistemáticamente derrotado. La doctrina de los hechos impeditivos y modificatorios es una derrotabilidad del tipo infra-incluyente, ya consolidada, que extiende la aplicación de la regla a un caso no contenido en ella, pero que comparte su justificación subyacente. La facilidad probatoria, como veremos en el próximo apartado, es también una derrotabilidad, pero de otro tipo.

\section{Derrotabilidad supraincluyente: facilidad probatoria}

Demostrado que el art. 1698 ha sido derrotado infrainclusivamente, cabe preguntarse, ¿si acaso también puede ser derrotado en el otro sentido, suprainclusivamente? Aquí también se trata de casos en que la generalización del art. 1698 no cuadra con su justificación. Mas lo propio de la suprainclusividad es que se trata de aquéllos que caen dentro de la generalización, pero no cumplen su justificación de primer ni de segundo orden. Las hipótesis de derrotabilidad suprainclusiva son, precisamente, las de facilidad probatoria.

La "facilidad probatoria" es una facultad del juez para invertir en juicio la carga de la prueba. El criterio para ejercer esa facultad es que una de las partes tiene un especial cercanía, disponibilidad o está en mejores condiciones para probar un determinado hecho, en contraste con la otra parte que, si bien tiene la carga según las reglas generales, está imposibilitada, o le es en exceso difícil, probar ese mismo hecho. Para comprender esta institución voy a revisar tres ejemplos de facilidad probatoria contrarias

${ }^{46}$ Corte Suprema, rol 1096-2009 (25 de agosto de 2010). La Corte después reiteró, literalmente, el mismo argumento en 86-09 (31 de agosto de 2010); 6331-2009 (26 de enero de 2011); 5234-09 (26 de enero de 2011); 6657-2009 (27 de enero de 2011); 7568-2009 (26 de marzo de 2011); 8792-2009 (25 de mayo de 2011); 6069-2009 (24 de junio de 2011). 
al art. 1698. Los primeros dos son casos hipotéticos y el tercero es real. Primero, un ejemplo de inversión de la carga en razón de facilidad respecto de la prueba de la existencia del contrato para el acreedor (a) que pasa a estar a cargo del deudor; el segundo trata de la inversión por facilidad de la carga de la extinción para el deudor (b) que pasa a estar a cargo del acreedor y el tercero (c) es un fallo de 2008 de la Corte de Apelaciones de Concepción.

\section{a) Derecho del consumidor}

Según el art. 1698 corresponde la prueba de la existencia de la obligación al acreedor que la alega. En una relación de consumo, cuando el consumidor exige el cumplimiento del proveedor, según el criterio general del beneficio del art. 1698, correspondería probar la existencia del contrato, no a al proveedor, sino al consumidor. Sin embargo, respecto de productos o servicios prosaicos y esporádicos -como la compra de un libro o el despacho a domicilio de una pizza- probablemente el consumidor un par de días después ya no conservará prueba alguna de ese contrato que celebró. En esos casos, el que mejor conserva prueba de los contratos es el proveedor -es decir, la librería o la pizzería- porque para él es importante llevar un registro detallado de sus ventas.

40 Bajo la regla del art. 1698, el proveedor -que sería el deudor sólo con la carga de las extinciones- no le correspondería presentar ese registro de ventas como prueba de la existencia del contrato porque ésa sería prueba de carga del consumidor-acreedor. Pero como el consumidor suele no conservar prueba de productos prosaicos y esporádicos, entonces la existencia del contrato quedaría sin prueba en juicio a pesar de que -y esto es lo importante- sí había alguien (el proveedor) con prueba suficiente para acreditarlo.

En el caso del producto prosaico, entonces, la aplicación del art. 1698 fallaría en colocar los incentivos correctos para que los hechos se prueben. Dicho en los términos de Frederick Schauer, el producto prosaico cae dentro de la generalización del art. 1698 y cae también en el criterio del beneficio (cumple la justificación de primer orden). Pero al asignarle la carga de probar el contrato al consumidor, en este contexto, no se logran distribuir los incentivos para que el hecho se pruebe (incumple la justificación de segundo orden) porque el cargado (el consumidor) no es el que puede probar la existencia del contrato.

En este primer ejemplo de facilidad probatoria, entonces, existe un descuadre grave entre, por una parte, la generalización con la justificación de primer orden y, por la otra, la justificación de segundo orden. Por lo tanto, respecto del producto prosaico, la aplicación del art. 1698 (que asignaba la carga probatoria del contrato al acreedor) merece ser derrotada suprainclusi- 
vamente. A cambio, la carga de la prueba debe invertirse judicialmente hacia el proveedor (la librería y la pizzería, deudores sin la carga de la obligación), que sí llevan el registro de los contratos celebrados -derrotando así la regla del art. 1698 que en el origen no le asignaba esa carga- porque de este modo se logrará que los incentivos se coloquen de manera correcta para que los hechos se prueben, honrando la justificación subyacente de segundo orden.

\section{b) Pago periódico marginal}

Pensemos en una tarjeta de crédito cuyo titular, cuando la utiliza, suele dividir el pago en varias cuotas pequeñas; o el dueño de numerosos estacionamientos que tiene múltiples arrendatarios de cada una de las oficinas o departamentos de un edificio. Estos dos casos tienen en común que para una de las partes el pago de esta obligación es un evento relativamente marginal respecto de sus actividades totales (el titular de la tarjeta y los arrendatarios, ambos obligados a un pago periódico marginal); mientras que para la otra parte el seguimiento de estos pagos es su actividad principal (el Banco que emite la tarjeta de crédito, el arrendador de los estacionamientos).

Según el art. 1698 la carga de probar las extinciones corresponde al deudor. Aplicando esta regla, entonces, la prueba del pago periódico marginal correspondería al titular de la tarjeta y al arrendatario del estacionamiento. No obstante, pasado un tiempo, tanto el titular de la tarjeta como el arrendatario probablemente ya no conservarán prueba de todos sus pagos anteriores y tendrán períodos vacíos en esa continuidad. Viceversa, según el art. 1698 al Banco y al arrendador les corresponde la prueba de la existencia de los contratos, pero no les corresponde la prueba de los pagos porque, según la misma regla, son extinciones a cargo del deudor. Con todo, como el seguimiento de los pagos es la actividad principal del Banco y del arrendador de estacionamientos, es probable que ellos lleven -al igual que la librería o la pizzería en el ejemplo anterior- un registro detallado.

En consecuencia, si aquí el Banco o el dueño de los estacionamientos demandaran el cumplimiento del contrato -exigiendo, supongo, el cumplimiento de ciertos pagos periódicos ya bastante pretéritos- a ellos les bastará con probar el contrato, pero no los pagos. Según el art. 1698 los pagos corresponderán a los deudores -el titular de la tarjeta y los arrendatarios de los estacionamientos-. Si bien es a ellos a quienes beneficia la prueba de esos hechos (y por eso el art. 1698 les asignó la carga inicialmente), no son los que pueden probarlos. Como se trata de pagos marginales, probablemente los demandados tendrán brechas sin prueba a la hora de acreditar la continuidad de sus pagos periódicos. El resultado de la aplicación del art. 1698 sería, entonces, que en la demanda de cumplimiento del Banco o el dueño de los estacionamientos contra 
el titular de la tarjeta o el arrendatario, estos últimos perderían porque tendrían brechas en la prueba de esos pagos periódicos marginales siendo que -esto es lo importante nuevamente- sí había alguien (el Banco y el arrendador) que tenía prueba suficiente de la continuidad esos pagos.

En el caso del pago periódico marginal, entonces, la aplicación del art. 1698 fallaría una vez más en colocar los incentivos correctos para que los hechos se prueben. En los términos de Frederick Schauer, el pago periódico marginal encaja en la formulación del art. 1698 (cabe dentro de la generalización), se cumple también el criterio del beneficio (justificación de primer orden), pero asignarle la carga de probar la extinción al titular de la tarjeta o al arrendatario no cumple su justificación subyacente de segundo orden. De aplicar el art. 1698 no se estarán colocando los incentivos para que los hechos se prueben (segundo orden) porque el cargado (el titular de la tarjeta o el arrendatario) no es el que puede probar la extinción de la obligación, no depende de él porque la prueba no está en sus manos.

En este segundo ejemplo de facilidad probatoria, también existe un descuadre grave entre la generalización y su justificación. Respecto del pago periódico marginal, la aplicación del art. 1698 (que asigna la carga probatoria de la extinción al deudor) merece ser derrotada suprainclusivamente también. A cambio, la carga de la prueba debe invertirse judicialmente hacia el Banco o el dueño de estacionamientos porque son ellos cuya actividad principal es llevar registro de los pagos -derrotando así la regla del art. 1698 que originalmente no le asignaba esa carga- porque de este modo se logrará que los incentivos se coloquen en forma correcta para que los hechos se prueben (segundo orden).

c) En el año 2008 la Corte de Apelaciones de Concepción dictó un fallo que acoge la doctrina de la facilidad probatoria en los siguientes términos:

"El Banco demandado al contestar la demanda, no reconoció haber dado la información errónea. Sin embargo, no acompañó a los autos copia de los antecedentes que hizo llegar a la Superintendencia, lo que debió hacer, pues es evidente que toda esa información consta en sus registros. No se ve ninguna razón, para no haber puesto a disposición del tribunal una copia de la información entregada al organismo contralor. Es un principio generalmente aceptado en materia probatoria que la prueba debe aportarla quien esté en mejores condiciones de hacerlo" $"$.

${ }^{47}$ Corte de Apelaciones de Concepción, 3 de octubre de 2008, MJCH_MJJ18856, cons. $3^{\circ}$ (redacción de René Ramos). Citado por Larroucau (2011), p. 518. 
Este tercer ejemplo, en rigor, no es distinto a los anteriores. $\mathrm{Al}$ igual que en la librería, la pizzería y el dueño de los estacionamientos, la carga de la prueba en principio no le correspondía al Banco. Las reglas generales asignan la carga de probar el hecho que causa el daño no al supuesto causante (el Banco) sino que a la víctima. La distribución de cargas según el beneficio del art. 1698 deja en una situación inmejorable al Banco: él tiene la prueba, pero no es él el cargado de probar.

Pese a ello, aquí el tribunal asignó la carga de probar el hecho que causa el daño (información errónea) al Banco, es decir, derrotó esa regla general. El argumento fue que el Banco indudablemente cuenta con registros de esos informes, de un modo similar a la librería y la pizzería que llevan un registro de sus ventas y al dueño de estacionamientos con el registro de los pagos que recibe. El razonamiento de la Corte de Apelaciones de Concepción -visto desde el marco conceptual de Frederick Schauer- sería una derrotabilidad suprainclusiva porque la justificación subyacente de primer orden traiciona a la de segundo. Si bien el Banco tiene un acceso fácil a esos informes, que constituyen la prueba decisiva de la información errónea, obviamente no le conviene presentarlos. En consecuencia, de seguir aplicando el criterio del beneficio (justificación de primer orden) no se lograría que los hechos se prueben (justificación de segundo orden) porque al que beneficia que el hecho quede probado no tiene la prueba (víctima) y el que tiene la prueba no le beneficia que el hecho se pruebe (Banco). El verdadero modo de honrar el art. 1698, estaría concluyendo la Corte, exige aquí aplicarlo a un caso que no cae dentro de la generalización que formula, pero que comparte su justificación. Queda, entonces, justificado cargar al Banco de probar la información errónea, a pesar que de según el criterio del beneficio esa carga no le corresponde, porque así se logra colocar los incentivos correctos para que los hechos se prueben. Esto es, queda justificado derrotar el art. 1698.

En suma, los casos de facilidad probatoria -al igual que el desfile motorizado por el medallista olímpico en el ejemplo de Frederick Schauer- caben dentro de la generalización que formula la regla, también se cumple la justificación subyacente de primer orden, pero se traiciona la justificación de segundo orden. Si se asigna la carga de la prueba al sujeto favorecido con la prueba del hecho (cumple el primer orden del beneficio), pero que no tiene en sus manos los medios para probarlo, los incentivos no estarán siendo distribuidos de modo tal que los hechos se prueben (traiciona el segundo orden). En conclusión, en los casos de facilidad probatoria merecen la derrotabilidad suprainclusiva del art. 1698, es decir, que el juez invierta la carga de la prueba en juicio. 


\section{CONClusión}

Este artículo trató acerca de la carga de la prueba en la responsabilidad civil contractual. En concreto, se analizó si acaso la regla general del art. 1698 del $C C$ puede ser derrotada. Para abordar este tema se utilizó el marco conceptual aportado por Frederick Schauer, que entiende las reglas jurídicas como generalizaciones que tras de sí tienen justificaciones de primer y segundo orden. La derrotabilidad es el descuadre grave entre la generalización de la regla y su justificación.

Acode con ese marco, se abordó el art. 1698. Se vio que en cuanto generalización selectiva, omite si el cargado dispone de la prueba en sus manos. Después de repasar sus posibles justificaciones subyacentes de primer orden, se concluyó que el mejor candidato es el criterio del beneficio. La justificación de segundo orden, el por qué del criterio del beneficio, notamos que es la distribución inteligente de incentivos para que los hechos se prueben.

Aclaradas cuales son las justificaciones subyacentes, se identificaron los casos hipotéticos y la jurisprudencia de derrotabilidad del art. 1698. Aquí se demostró que la doctrina de los hechos impeditivos y modificatorios son un caso de derrotabilidad infraincluyente. A su turno, la facilidad probatoria es también un caso de descuadre entre generalización y justificación, pero esta vez es una derrotabilidad supraincluyente.

\section{Bibliografía}

Alchourrón, Carlos (1996). "On Law and Logic". Ratio Juris, N Ix, Oxford. Alessandri, Arturo, Manuel Somarriva y Antonio Vodanovic (1991). Derecho Civil. Parte Preliminar y Parte General. Santiago: Editorial Conosur.

Atria, Fernando (2000). "Las circunstancias de la derrotabilidad". Revista de Ciencias Sociales, No XLv, Valparaíso.

Chiovenda, Giusseppe (2005). Instituciones de Derecho Procesal Civil. Buenos Aires: Editorial Valletta, vol. 3, tomo I.

Comoglio, Luigi Paolo, Ferri Corrado y Michele Taruffo (1995). Lezioni Sul Processo Civile. I. Il Proceso Ordinario Di Cognizione. Bologna: Il Mulino.

Departamento de Derecho Privado de la Universidad de Chile (2012). "Comentarios al proyecto del nuevo Código Procesal Civil”. Santiago. Disponible en-línea en www.reformasprocesales.udp.cl/wp-content/uploads/2010/09/ observacionesdelDepartamentodeDerecho.pdf visitada el 14 de enero de 2013

Ferrer, Jordi y Giovanni BatTista (eds.) (2012). The Logic of Legal Requirements: Essays on Defeasibility. Oxford: Oxford University Press. 
Fuller, Lon (1958). "Postivisim and fidelity to law - A reply to profesor Hart". Harvard Law Review, vol. LXXI, $\mathrm{N}^{\circ}$ 4, Cambridge.

HART, Herbert Lionel Adolphus (1958). "Positivism and the separation of law and morals". Harvard Law Review, vol. LXXI, N¹, Cambridge.

LARroucau, Jorge (2011). "Res Ipsa Loquitur: Quien habla es el juez, no la cosa”. Gonzalo Figueroa, Enrique Barros y Mauricio TAPiA (eds.). Estudios de Derecho Civil. Santiago: Editorial Legal Publishing.

MARín, Juan Carlos y Jorge VIDAL (2012). "Comentarios a carta de profesores de Derecho Civil sobre proyecto de ley que aprueba Código Procesal Civil". Revista de Derecho Procesal de la Universidad de Chile, $\mathrm{N}^{\circ}$ XXII, Santiago.

Marinoni, Luiz Guilherme y Sergio Cruz Arenhart (2009). Prova. São Paulo: Editoriais Revista dos Tribunais.

Pizarro, Carlos (2008). "La culpa como elemento constitutivo del incumplimiento en las obligaciones de medio o diligencia". Revista de Derecho de la Pontificia Universidad Católica de Valparaíso, vol. xxxi, Valparaíso.

"Proyecto de Ley que establece un nuevo Código Procesal Civil (Boletín No 8596-07)" (2012). Revista de Derecho Procesal de la Universidad de Chile, N $^{\circ}$ xxII, Santiago.

PRÜtTing, Hanns (2010). "Carga de la prueba y estándar probatorio: la influencia de Leo Rosenberg y Karl Hainz Schawb para el desarrollo del moderno Derecho Probatorio". Ius et Praxis, vol. XVI, $\mathrm{N}^{\circ} 1$, Talca.

RóDENAS, Ángeles, 1983. "En la penumbra: indeterminación, derrotabilidad y aplicación judicial de normas". Doxa Cuadernos de Filosofía del Derecho, vol. XXIV, Alicante. Disponible en línea en: http://publicaciones.ua.es/filespubli/ pdf/02148678RD23080718.pdf, visitada el 14 dde enero de 2013.

Rodriguez, Jorge (2012). "Against Defeasibility of Legal Rules". Jordi FerRer and Giovanni BatTista (eds.). The Logic of Legal Requirements: Essays on Defeasibility. Oxford: Oxford University Press.

Schauer, Frederick (1998). "On the Supposed Defeseability of Legal Rules". Current Legal Problems, $\mathrm{N}^{\circ}$ LI, Oxford.

Schauer, Frederick (1991). Playing by the Rules. A Philosopical Examination of RuleBased Decision-Making in Law and Life. Oxford,:Editorial Clarendon Press.

TAVolari, Raúl (2012). “¿Confianza o desconfianza en los jueces?: Un alegato a favor de conferir mayores oportunidades a la justicia, a propósito de la polémica por las cargas probatorias dinámicas o principio de facilidad de la prueba". Revista de Derecho Procesal de la Universidad de Chile, $\mathrm{N}^{\circ}$ xxII, Santiago .

VIDAL, Álvaro (2010). "Incumplimiento y atribución de responsabilidad en las obligaciones de medio y resultado (a propósito de una sentencia de la Corte Suprema No ingreso 1771-2008)". Estudios de Derecho Civil, vol. v, Concepción.

VV.AA. (2012). "Carta comentarios al Proyecto de Ley que establece el Código Procesal Civil (Boletín 8197-07)". Revista de Derecho Procesal de la Universidad de Chile, $\mathrm{N}^{\circ}$ XxII, Santiago. 
茂

은

(1)

U

$\frac{\text { 을 }}{\frac{3}{3}}$

46

\section{Jurisprudencia de la Corte Suprema}

Rol 1096-2009 (25 de agosto de 2010).

Rol 86-09 (31 de agosto de 2010).

Rol 6331-2009 (26 de enero de 2011).

Rol 5234-09 (26 de enero de 2011).

Rol 6657-2009 (27 de enero de 2011).

Rol 7568-2009 (26 de marzo de 2011).

Rol 8792-2009 (25 de mayo de 2011).

Rol 6069-2009 (24 de junio de 2011). 